\title{
Selective deficits in developmental cognitive neuropsychology: An introduction
}

\author{
Bradley C. Duchaine \\ Institute of Cognitive Neuroscience, University College London, UK
}

Traditionally, neuropsychologists have studied selective impairments in patients who suffered brain damage as adults. These selective impairments have revealed much about cognitive organization in normal brains (Shallice, 1988; Zeki, 1993) and have initiated major research programmes (Forde \& Humphreys, 2002; Milner \& Goodale, 1995; Shallice, 1988; Yin, 1969; Zeki, 1993). In addition, analysis of lesion location in patients with selective deficits has been critical for the localization of cognitive mechanisms (Broca, 1861; Milner \& Goodale, 1995; Scoville \& Milner, 1957).

Although most documented selective impairments were caused by brain damage in adulthood, selective impairments can also result from developmental disorders. Rather than suffering damage to particular mature cognitive mechanisms, individuals with selective developmental disorders fail to develop certain cognitive mechanisms. A number of developmental disorders have been investigated using a cognitive neuropsychology approach (Baron-Cohen, Leslie, \& Frith, 1985; Butterworth, 1999; Coltheart, Masterson, Byng, Prior, \& Riddoch, 1983; Temple, 1989, 1997), and recent years have seen growing interest in selective developmental disorders (Blair, 2005; Duchaine \& Nakayama, 2005; Klein, Cosmides, Murray, \& Tooby, 2004; Nijboer, van Zandvoort, \& de Haan, in press; Peretz \& Hyde,
2003; Temple \& Richardson, 2004). Selective developmental deficits have also generated considerable discussion in recent years (see Thomas \& Karmiloff-Smith, 2002, and the commentaries), with some even suggesting that such deficits are unlikely to exist (Karmiloff-Smith, Scerif, \& Ansari, 2003; Thomas \& Karmiloff-Smith, 2002).

\section{SUMMARY OF THE PAPERS}

This special issue presents four papers that showcase the power and promise of cognitive neuropsychology approaches to selective developmental disorders. Collectively the papers demonstrate that developmental disorders can contribute to a range of research areas and address varied questions within an area. The papers investigate selective developmental deficits affecting four abilities: spatial perception, face perception, reading, and memory. They also differ in their aims. Three papers attempt to determine the nature of the impaired mechanisms giving rise to the disorder (Duchaine, Yovel, Butterworth, \& Nakayama, 2006; Temple \& Richardson, 2006; White, Frith, Milne, Rosen, Swettenham, \& Ramus, 2006), and White et al. (2006) also test a hypothesis about the etiology of dyslexia. In contrast, McCloskey, Valtonen, and Sherman (2006) use the pattern of errors made in spatial tasks to

Correspondence should be addressed to Bradley C. Duchaine, Institute of Cognitive Neuroscience, University College London, Alexandra House, 17 Queen Square, London WC1 N 3AR, UK (Email: b.duchaine@ucl.ac.uk). 
develop a theory of how object orientation is represented. Despite their differences, all the papers interpret their results within standard cognitive models or, in the case of McCloskey et al., propose a cognitive model to account for their results. Each paper also discusses the issues that researchers face when making inferences from selective developmental deficits.

In a series of papers, McCloskey and colleagues (McCloskey \& Palmer, 1996; McCloskey \& Rapp, 2000a, 2000b; McCloskey et al., 1995) have documented the severe visual localization deficits experienced by a young woman, AH, with no history of neurological damage and many normal visual abilities. On tasks requiring $\mathrm{AH}$ to point to the location at which an object appeared, she pointed to the opposite side of the display on half of the trials. Amazingly, even though she was unable to judge the side on which the object was presented, she accurately indicated the distance of the object from the centre of the display. Her pattern of errors led to the proposal that object location is represented by separately specifying the distance of the object and the direction of the object from a reference point in a spatial coordinate system (McCloskey et al., 1995). In this issue, McCloskey, Valtonen, and Sherman (2006) extend their coordinatesystem hypothesis to the representation of object orientation. They report results from three subjects with object-orientation deficits and demonstrate that their extension of the coordinate-system hypothesis can account for the subjects' striking errors.

In the second article, my colleagues and I (Duchaine, Yovel, Butterworth, \& Nakayama, 2006) take a new approach to prosopagnosia. For years, cognitive neuroscientists have debated whether face processing involves content-specific mechanisms specialized for faces. To address this issue with a more systematic approach than past case studies of prosopagnosia, we tested the predictions of each alternative to the face-specific account. Our results were inconsistent with each alternative hypothesis and thus implicate impairments to face-specific mechanisms. In addition, the results indicate that the construction of face- specific mechanisms involves a developmental process not involved in the development of other visual recognition mechanisms.

The sensorimotor hypothesis of developmental dyslexia proposes that the phonological deficits underlying reading problems in dyslexia arise due to preexisting sensorimotor impairments. In the third article, White, Frith, Milne, Rosen, Swettenham, and Ramus (2006) test the predictions of the sensorimotor hypothesis with a powerful combination of approaches. First, they examined whether developmental dyslexia is invariably accompanied by sensorimotor impairments. Consistent with other results (Ramus et al., 2003), many children with dyslexia were normal with sensorimotor tasks. However, because the dyslexic children were more likely to have sensorimotor impairments than control children, sensorimotor impairments may be a sufficient but not a necessary cause of reading impairments. If so, sensorimotor impairments should lead to reading impairments. Autistic children have higher rates of sensorimotor impairments than normal children, so the authors assessed the sensorimotor and reading abilities of a group of autistic children. The autistic children showed a mixture of normal and impaired performance on both the sensorimotor measures and the reading measures. Critically, many autistic children with sensorimotor impairments had normal reading skills, and the occurrence of sensorimotor impairments within the autistic group was entirely independent of the occurrence of reading impairments. Hence, the combination of results from dyslexic and autistic subjects reveals a double dissociation between sensorimotor ability and reading ability, which strongly suggests that developmental dyslexia is not caused by sensorimotor impairments.

Cognitive theories of memory propose the existence of multiple memory systems that carry out different functions (Schacter \& Tulving, 1994). Past work has found that some of these systems are developmentally dissociable (Temple \& Richardson, 2004; Vargha-Khadem et al., 1997). Temple and Richardson (2006) extend this work by demonstrating a new set of 
dissociations. In particular, they studied the case of MM, a nine-year-old boy without any history of brain damage. MM's results showed intact visual episodic memory and normal learning over repeated trials. In contrast, he had deficits with verbal episodic memory, autobiographical episodic memory, and semantic memory.

\section{DEVELOPMENTAL DEFICITS AND THE TRANSPARENCY ASSUMPTION}

Some researchers have argued that developmental disorders, unlike acquired disorders, are unlikely to be properly described within standard cognitive theories and should not be used to draw inferences about normal cognition or normal cognitive development (Karmiloff-Smith et al., 2003; Thomas \& Karmiloff-Smith, 2002). Neuropsychological inferences are based on a number of assumptions (Caramazza, 1986; Shallice, 1988), one of which is the transparency assumption, ${ }^{1}$ which maintains that overall cognitive organization in cases with neuropsychological impairments is normal except for the impaired mechanisms and their outputs (Caramazza, 1986, 1992). Violation of the transparency assumption is argued to be especially likely in developmental disorders, because plasticity in developing brains is likely to lead to atypical cognitive mechanisms and overall organization (Thomas \& Karmiloff-Smith, 2002).

Because cognitive reorganization may occur after brain damage, similar concerns also apply to studies with acquired disorders. Shallice (1988) suggests two defences against misleading dissociations due to reorganization after brain damage, and these are also applicable to developmental disorders. First, inferences should be based on classical dissociations, which contrast normal performance on one task with impaired performance on another task, rather than dissociations in which performance on neither task is normal. Classical dissociations are stronger evidence for dissociability, because they suggest that the mechanism carrying out the task performed normally is not impaired. The second defence against spurious dissociations is the double dissociation. Spurious double dissociations could arise only if damage to a mechanism or a failure to develop it led to opposite dissociations in different individuals. While possible, such an outcome seems unlikely.

The fit between normal models of cognition and results from acquired cases indicates that the transparency assumption is not violated after brain damage. Similarly, past studies (Temple, 1997) and the papers in this issue suggest that normal cognitive models effectively account for selective impairments in developmental disorders, but undoubtedly this issue will continue to be an important topic in developmental cognitive neuropsychology.

\section{DEVELOPMENTAL DISORDERS AND DEVELOPMENTAL MODULARITY}

The preceding discussion suggests that developmental disorders, like acquired disorders, can contribute to models of normal cognition. However, developmental disorders also can provide additional information not supplied by acquired disorders. Dissociations in developmental disorders are not only functional dissociations, but also reveal dissociations between developmental processes (Temple, 1997).

For example, if a subject with a developmental disorder is normal with tasks measuring Ability A and severely impaired with tasks for Ability B, this dissociation suggests that the cognitive mechanisms underlying Ability A developed normally while those underlying Ability B did not. This developmental dissociation indicates that the development of the cognitive mechanisms for Ability A rely on different developmental

\footnotetext{
${ }^{1}$ The transparency assumption is similar to Shallice's subtractivity assumption (1988) and Thomas and Karmiloff-Smith's assumption of residual normality (2002).
} 
processes than do the mechanisms giving rise to Ability B. A double dissociation, like that seen in White et al. (2006), would indicate that the mechanisms for both abilities involve different developmental processes. Note, however, that the developmental dissociability of two cognitive mechanisms does not imply that their construction does not involve any of the same developmental processes, but only that they involve at least some different processes. ${ }^{2}$

\section{FUTURE DIRECTIONS}

Although the investigations of selective developmental deficits in this issue utilize behavioural measures to address cognitive and developmental issues, the study of selective developmental impairments also holds great promise for other research issues. Our understanding of the genetic basis of cognition is certain to increase enormously in the near future, and research into selective developmental disorders will contribute much to this exciting area (Fisher \& DeFries, 2002; MacDermot et al., 2005; Meyer-Lindenberg et al., 2004). Selective developmental disorders, like selective acquired disorders, also provide a means to determine the location of cognitive functions (Meyer-Lindenberg et al., 2004; Molko et al., 2003). Research is also likely to uncover procedures that ameliorate selective deficits and lessen the difficulties created by these deficits (Merzenich et al., 1996; Temple et al., 2003).

Many questions can be addressed through these disorders, and the most powerful approaches will combine cognitive, neural, and genetic analyses in longitudinal studies (Ramus, 2004; Temple, 2003). Multi-faceted approaches will be demanding, but a deep understanding of these fascinating conditions will be an exceptional scientific achievement.

PrEview proof published online 30 March 2006

\section{REFERENCES}

Baron-Cohen, S., Leslie, A. M., \& Frith, U. (1985). Does the autistic child have a "theory of mind"? Cognition, 21, 37-46.

Blair, R. J. R. (2005). Applying a cognitive neuroscience perspective to the disorder of psychopathology. Developmental Psychopathology, 17, 865-891.

Broca, P. (1861). Remarques sur le siege de la faculte de langage articule, suivies d'une observation d'aphemie. Bulletin de la Societe Anatomique, 6, 330-357.

Butterworth, B. (1999). The mathematical brain. London: Macmillan.

Caramazza, A. (1986). On drawing inferences about the structure of normal cognitive systems from the analysis of patterns of impaired performance: The case for single-patient studies. Brain E Cognition, 5, 41-66.

Caramazza, A. (1992). Is cognitive neuropsychology possible? Journal of Cognitive Neuroscience, 4, 80-95.

Coltheart, M., Masterson, J., Byng, S., Prior, M., \& Riddoch, M. J. (1983). Surface dyslexia. Quarterly Journal of Experimental Psychology, 35, 469-495.

Duchaine, B., \& Nakayama, K. (2005). Dissociations of face and object recognition in developmental prosopagnosia. Journal of Cognitive Neuroscience, 17, 249-261.

Duchaine, B., Yovel, G., Butterworth, E.J., \& Nakayama, K. (2006). Prosopagnosia as an impairment to face-specific mechanisms: Elimination of the alternative hypotheses in a developmental case. Cognitive Neuropsychology, 23, 714-747.

Fisher, S., \& DeFries, J. C. (2002). Developmental dyslexia: Genetic dissection of a complex cognitive trait. Nature Neuroscience Revierws, 3, 767-780.

Forde, E. M. E., \& Humphreys, G. W. (2002). Category-specificity in mind and brain. Hove, UK: Psychology Press.

Karmiloff-Smith, A., Scerif, G., \& Ansari, D. (2003). Double dissociations in developmental disorders? Theoretically misconceived, empirically dubious. Cortex, 39, 161-163.

Klein, S., Cosmides, L., Murray, E., \& Tooby, J. (2004). On the acquisition of knowledge about personality traits: Does learning about the self engage different mechanisms than learning about others? Social Cognition, 22, 367-390.

MacDermot, K. D., Bonora, E., Sykes, N., Coupe, A.-M., Lai, C., Vernes, S. C., Vargha-Khadem, F., McKenzie,

\footnotetext{
${ }^{2}$ In fact, given that the entire brain develops from a single cell, the construction of all cognitive mechanisms involves many shared developmental processes.
} 
F., Smith, R. L., Monaco, A. P., \& Fisher, S. E. (2005). Identification of FOXP2 truncation as a novel cause of developmental speech and language deficits. American Journal of Human Genetics, 76, 1074-1080.

McCloskey, M., \& Palmer, E. (1996). Visual representation of object location: Insights from localization impairments. Current Directions in Psychological Science, 5, 25-28.

McCloskey, M., \& Rapp, B. (2000a). A visually based developmental reading deficit. Journal of Memory and Language, 43, 157-181.

McCloskey, M., \& Rapp, B. (2000b). Attentionreferenced visual representations: Evidence from impaired visual localization. Journal of Experimental Psychology: Human Perception and Performance, 26, 917-933.

McCloskey, M., Rapp, B., Yantis, S., Rubin, G., Bacon, W. F., Dagnelie, G., Gordon, B., Aliminosa, D., Boatman, D. F., Badecker, W., Johnson, D. N., Tusa, R. J., \& Palmer, E. (1995). A developmental deficit in localizing objects from vision. Psychological Science, 6, 112-117.

McCloskey, M., Valtonen, J., \& Sherman, J. (2006). Representing orientation: A coordinate-system hypothesis, and evidence from developmental deficits. Cognitive Neuropsychology, 23, 680-713.

Merzenich, M. M., Jenkins, W. M., Johnston, P., Schreiner, C., Miller, S. L., \& Tallal, P. (1996). Temporal processing deficits of language-learning impaired children ameliorated by training. Science, 271, 77-81.

Meyer-Lindenberg, A., Kohn, P., Mervis, C. B., Kippenhan, J. S., Olsen, R. K., Morris, C. A., Berman, K. F. (2004). Neural basis of genetically determined visuospatial construction deficit in Williams syndrome. Neuron, 43, 623-631.

Milner, A. D., \& Goodale, M. A. (1995). The visual brain in action. New York: Oxford University Press.

Molko, N., Cachia, A., Riviere, D., Mangin, J. F., Bruandet, M., Le Bihan, D., et al. (2003). Functional and structural alterations of the intraparietal sulcus in a developmental dyscalculia of genetic origin. Neuron, 40, 847-858.

Nijboer, T. C. W., van Zandvoort, M. J. E., \& de Haan, E. H. F. (in press). Covert colour processing in colour agnosia. Neuropsychologia.

Peretz, I., \& Hyde, K. L. (2003). What is specific to music processing? Insights from congenital amusia. Trends in Cognitive Sciences, 7, 362-367.

Ramus, F. (2004). Neurobiology of dyslexia: A reinterpretation of the data. Trends in Neurosciences, 27, 720-726.
Ramus, F., Rosen, S., Dakin, S. C., Day, B. L., Castellote, J. M., White, S., \& Frith, U. (2003). Theories of developmental dyslexia: Insights from a multiple case study of dyslexic adults. Brain, 126, 841-865.

Schacter, D. L., \& Tulving, E. (1994). Memory systems. Cambridge, MA: MIT Press.

Scoville, W. B., \& Milner, B. (1957). Loss of recent memory after bilateral hippocampal lesions. Journal of Neurology, Neurosurgery E' Psychiatry, 20, 11-21.

Shallice, T. (1988). From neuropsychology to mental structure. Cambridge, UK: Cambridge University Press.

Temple, C. M. (1989). Digit dyslexia: A categoryspecific disorder in developmental dyscalculia. Cognitive Neuropsychology, 6, 93-116.

Temple, C. M. (1997). Developmental cognitive neuropsychology. Hove, UK: Psychology Press.

Temple, C. M., \& Clahsen, H. (2002). How connectionist simulations fail to account for developmental disorders in children. Behavioral and Brain Sciences, 25, 769-770.

Temple, C. M., \& Richardson, P. (2004). Developmental amnesia: A new pattern of dissociation with intact episodic memory. Neuropsychologia, 42, 764-781.

Temple, C. M., \& Richardson, P. (2006). Developmental amnesia: Fractionation of developing memory systems. Cognitive Neuropsychology, 23, $762-788$.

Temple, E., Deutsch, G. K., Poldrack, R. A., Miller, S. L., Tallal, P., Merzenich, M. M., \& Gabrieli, J. D. E. (2003). Neural deficits in children with dyslexia ameliorated by behavioural remediation: Evidence from fMRI. Proceedings of the National Academy of Sciences, 100, 2860-2865.

Thomas, M., \& Karmiloff-Smith, A. (2002). Are developmental disorders like cases of adult brain damage? Implications from connectionist modelling. Behavioral and Brain Sciences, 25, 727-788.

Vargha-Khadem, F., Gadian, D. G., Watkins, K. E., Connelly, A., Van Paesschen, W. V., \& Mishkin, M. (1997). Differential effects on early hippocampal pathology on episodic and semantic memory. Science, 277, 376-380.

White, S., Frith, U., Milne, E., Rosen, S., Swettenham, J., \& Ramus, F. (2006). A double dissociation between sensorimotor impairments and reading disability: A comparison of autistic and dyslexic children. Cognitive Neuropsychology, 23, 748-761.

Yin, R.K. (1969). Looking at upside-down faces. Journal of Experimental Psychology, 81, 141-145.

Zeki, S. (1993). A vision of the brain. Oxford: Blackwell. 